\title{
TRIZ Basic Learning Method Through Linkage with Interests
}

\section{관심 분야와의 연계를 통한 TRIZ 기초 학습방법}

\author{
Jea-Hyun Heo ${ }^{1}$, Yong-Won Song ${ }^{2}$ \\ 허재현 ${ }^{1}$, 송용원 2 \\ ${ }^{1}$ Engineer, DP Tech, SK Hynix Semiconductor Co., Ltd., Korea, jeahyun.hu@sk.com \\ ${ }^{2}$ Professor, Nano \& Semiconductor Engineering, Korea Polytechnic Univ., Korea, ywsong@kpu.ac.kr
}

Corresponding author: Jea-Hyun Heo

\begin{abstract}
Amid the era of convergence and innovation that requires more creativity than human labor, a growing number of companies and schools are introducing TRIZ, a creativity-based problem-solving tool. However, it is not easy to learn and apply TRIZ theories that are different from existing methods. In particular, if the cases used in education are different from those of students' interests or if the learning content is too difficult, the learning effect will be even worse. In this paper, we conduct research on how to induce immersion of trainees and learn TRIZ theory efficiently. The effectiveness of education can be increased if students combine hobbies that they are interested in or examples of solving real problems at hand. Using DIY (Do It Yourself) production activities, which anyone can easily participate in with interest, the curriculum that solves various problems in the production process directly through TRIZ theory has gained active participation and excellent learning effects. It is a way to effectively understand Learning in conjunction with TRIZ and areas of interest is an effective way to understand TRIZ tools such as invention principles, material-field, and FORS(Function oriented Resource Search).
\end{abstract}

Keywords: TRIZ, Creativity, FORS, DIY, Simpl Flute, substance-field

요약: 인간의 노동력보다 창의력이 더욱 필요한 융합과 혁신의 시대가 된 가운데 창의력기반 의 문제해결 도구인 트리즈를 도입하는 기업이나 학교가 많이 증가하고 있다. 하지만 기존의 방법과 다른 트리즈 이론을 배우고 현장에 적용하는 것은 쉽지 않다. 특히 교육에 활용되는 사례가 교육생들의 관심분야와 다르거나 학습 내용이 너무 어려울 경우 학습효과는 더욱 떨 어진다. 본 논문에서는 교육생들의 몰입을 유도하고 효율적으로 트리즈 이론을 배울 수 있는 방법에 대한 연구를 진행하였다. 교육생들이 관심을 가지고 있는 취미활동이나 당면한 현실 문제해결 사례를 접목한다면 교육의 효과가 증가할 수 있다. 누구나 흥미를 느끼고 쉽게 참여 할 수 있는 악기 DIY(Do It Yourself) 제작활동을 활용하여 제작과정에서 발생하는 다양한 문제 를 트리즈 이론을 통해 직접 해결해 보는 교육 과정은 교육생들의 능동적 참여와 뛰어난 학습 효과를 얻게 했다. 트리즈와 관심 분야를 연계하는 것은 발명원리, 물질-장, FORS(Function oriented Resource Search) 같은 트리즈 도구들을 효과적으로 이해할 수 있는 방법이다.

핵심어: TRIZ, 창의성, 몰입, FORS, DIY, 심플플루트, 물질-장

Received: December 07, 2020; $1^{\text {st }}$ Review Result: January 21, 2021; $2^{\text {nd }}$ Review Result: March 11, 2021 Accepted: April 30, 2021 


\section{1. 트리즈(TRIZ)학습과 몰입}

\section{1 트리즈 개요}

러시아(옛 소비에트연방)의 겐리히 알츠슐러(Genrikh Saulovich Altshuller)는 해군의 특허파트에 근무하며 200 만 건 이상의 특허를 분석하여 그중에서 약 4 만 건의 창의적이고 우수한 특허를 추출해서 분석함으로써 문제해결 과정의 규칙성을 파악하여 정리한 트리즈 이론을 완성한다. 트리즈는 “발명문제해결이론” 으로 알려져있지만 창의적인 아이디어 발상 도구들이 다양한 “창의적 문제해결 기법” 이다[1].

트리즈는 문제해결 대상을 특정 분야에 국한하지 않고 다양한 분야에 적용하여 창의적 아이디어를 낼 수 있도록 도와준다. 또한 문제를 해결할 때만이 아니라 새로운 것을 만들어 내는 창조 활동에도 많은 도움을 준다는 것이 다양한 결과로 입증되고 있다.

\section{2 트리즈 학습과 몰입}

뛰어난 문제해결 효과를 가지고 있는 트리즈 이론은 국내외 기업에서 유용하게 활용되고 있다. 반도체 소자를 생산하는 SK하이닉스에서는 각 단계의 트리즈 교육과정이 마련되어 있으며 설비를 담당하는 전임직 사원들은 맡는 영역에서 발생한 문제를 직접 해결하기 위해 대다수 트리즈 교육을 이수하고 있다. 하지만, 트리즈 기초과정을 이수한 PKG Front 기술팀의 56명의 응답자를 대상으로 파악해본 결과 트리즈 학습 내용을 업무에 잘 활용하지 못하고 있는 것으로 파악되었다[표 1]. 학습한 트리즈 기법을 실무에 활용하는 방법에 대한 경험이 없고 또한, 기존의 문제해결 기법과 차별성이 있어서 활용하는 데 익숙하지 않기 때문이다. 이것은 교육과정에서 소개되는 대부분의 사례들은 학습대상자와 밀접한 관련이 없거나 교육 자체를 위한 것들인 점이 중요한 요인이라 할 수 있다.

[표 1] 트리즈 학습 후 활용도 조사 - 2019년 기초학습자 대상

[Table 1] TRIZ Post-Learning Utilization Survey - 2019 Basic Learners

\begin{tabular}{c|c|c}
\hline 간접 활용 & 미활용 & 기타 \\
\hline 5 명 & 48 명 & 3 명 \\
\hline $8.9 \%$ & $85.7 \%$ & $5.3 \%$ \\
\hline
\end{tabular}

트리즈를 배우고자 하는 학습자 입장에서 전혀 모르는 분야의 기술이나 관심도 없는 사례로 교육을 받게 되면 학습 몰입도는 반감되며 학습 후 효과 역시 크지 않을 것이다.

예를 들어 관심이 낚시에만 있는 사람에게 그다지 관련도 없는 음악과 관련된 이야기를 계속하면 대화가 지속할 수 없다. 이야기를 들어줄 수는 있지만, 흥미가 없으므로 상대방의 애기에 몰입할 수 없다. 그와 반대로 새로이 출시된 낚시용품이나 많은 물고기를 잡은 포인트에 관해 애기한다면 집중할 수밖에 없다. 이처럼 트리즈와 관심 분야와의 연계는 학습 과정의 몰입도를 높이고 학습 후 실무에 활용도를 높이기 위해서 필요하다. 
관심 분야가 있는 사람들은 결국 해당 분야에서 많은 흥미를 느끼게 되고 관련된 지식을 탐구하려는 상태에 도달한다. 일반적으로 이러한 상태는 취미나 특기에서 찾을 수 있으며 트리즈 교육에도 관심분야 사례를 접목하면 뛰어난 학습효과를 가지고 올 수 있을 것이다.

\section{2. 관심 분야와 연계한 트리즈 학습}

\subsection{DIY(Do It Yourself) 활동과 연계를 통한 트리즈 학습}

일반적으로 트리즈는 업무상 필요에 의해 배워야 하는 경우가 많다. 그러므로, 학습 과정에서 적지 않은 심리적 부담이 작용한다. 어떠한 학습이나 교육과정도 부담스럽다는 것은 부정적인 요소로 작용할 수밖에 없다. 이러한 부정적 심리를 줄여줄 수 있어야 학습 몰입도를 높일 수 있을 것이다. 따라서, 트리즈 학습 시 관심 분야의 문제를 연계하면 학습효과를 끌어 올릴 수 있는 하나의 방법이 될 것이다.

그렇다면 관심 분야와 트리즈의 연계는 어떤 형식으로 진행하면 될까? 트리즈 교육을 위해 모든 사람의 관심도를 확인하여 설계할 수도 없고 같은 관심사를 지닌 사람들만 따로 모아서 진행할 수도 없다. 그렇기 때문에, 학습자 스스로 관심이 있는 분야의 문제와 연계한 학습 방법이 대안이 될 수 있다. 기초 과정을 이수했다면 연습 삼아 적용해 볼 과제가 필요하며 이때 자신의 관심사, 즉 취미활동과 연계한 문제를 활용할 수 있다면 좋은 결과를 얻을 수 있다. 취미활동에서 발생할 수 있는 문제에 발명원리, 분리원리, 표준해 등 트리즈의 도구들을 활용해 보는 것이다. 자신의 문제를 스스로 풀어보는 것이기 때문에 몰입도가 높을 수밖에 없다.

오픈서베이가 20 50대 남녀를 대상으로 조사한 '취미생활-자기계발 트렌드 리포트 $2020^{\prime}$ 에 따르면 최근 음악과 공예 활동 등의 창조 활동을 하는 사람들의 비중이 과거 대비 늘어나고 있다는 것을 알 수 있다[그림 1],[2].

\begin{tabular}{|c|c|c|c|c|c|c|c|}
\hline \multirow{2}{*}{ घ1순위 $\square 1+2+3$ 순위 } & \multirow{2}{*}{ 전체 } & \multicolumn{6}{|c|}{ 직업 } \\
\hline & & 대학/원생 & 취준생 & 직장인 & 프리랜서 & 전업주부 & 무직/기타 \\
\hline (Base) & $(917)$ & $(101)$ & $(44)$ & $(503)$ & $(89)$ & $(120)$ & $(60)$ \\
\hline 스포츠/피트니스 (헬스, 등산 등) & 18.033 .6 & 31.7 & 27.3 & 38.0 & 27.0 & 25.0 & 31.7 \\
\hline \multirow{2}{*}{$\begin{array}{r}\text { 재테크/투자 관련 (주식, 부동산 투자 등) } \\
\text { 어학 (영어 등) }\end{array}$} & \begin{tabular}{l|l|l|} 
& 16.0 & 29.3
\end{tabular} & 13.9 & 15.9 & 37.2 & 20.2 & 23.3 & 25.0 \\
\hline & \begin{tabular}{|l|l|l|} 
& 14.7 & 26.1 \\
\end{tabular} & 41.6 & 38.6 & 24.3 & 20.2 & 21.7 & 23.3 \\
\hline 요리/음료/맛집 (베이킹, 커피, 와인 시음 등) & \begin{tabular}{|l|l|} 
& 10.7 \\
\end{tabular} & 15.8 & 25.0 & 20.9 & 24.7 & 30.0 & 28.3 \\
\hline 교양 (인문학, 독서, 공연관람 등) & \begin{tabular}{|l|l|} 
& 6.7 \\
\end{tabular} & 15.8 & 18.2 & 17.5 & 19.1 & 12.5 & 5.0 \\
\hline 컴퓨터/디자인 툴 (MS 오피스 등) & \begin{tabular}{|l|l} 
& 4.5 \\
\end{tabular} & 12.9 & 18.2 & 9.9 & 7.9 & 4.2 & 10.0 \\
\hline 공예/DIY (가죽/자수, 꽃꽂이 등) [ & 5.39 .3 & 2.0 & 6.8 & 7.4 & 12.4 & 20.8 & 11.7 \\
\hline 사진/영상제작 (촬영, 편집 등) & 3.58 .4 & 11.9 & 9.1 & 8.0 & 9.0 & 1.7 & 18.3 \\
\hline 음악 (보컬, 디제잉 등) & 3.87 .7 & 12.9 & 4.5 & 6.6 & 14.6 & 3.3 & 10.0 \\
\hline 패션/뷰티 (코디/메이크업/헤어 등) & 1.96 .8 & 8.9 & 13.6 & 5.4 & 7.9 & 8.3 & 5.0 \\
\hline 미술/캘리그라피 (인물화, 펜 드로잉 등) & 1.95 .3 & 7.9 & 6.8 & 3.6 & 6.7 & 8.3 & 6.7 \\
\hline 코딩/프로그래밍 (JAVA 등) & $\square 2.84 .4$ & 10.9 & 2.3 & 4.6 & 5.6 & 0.0 & 0.0 \\
\hline 파이낸스 (회계, 재무 등) & $\square 2.24 .4$ & 5.9 & 4.5 & 5.2 & 4.5 & 0.8 & 1.7 \\
\hline 마케팅 (네이버검색광고 등) [ & $\square 1.64 .3$ & 3.0 & 2.3 & 4.6 & 6.7 & 2.5 & 5.0 \\
\hline 데이터 분석 (파이썬/R 등) & $\square 1.62 .9$ & 8.9 & 6.8 & 2.8 & 0.0 & 0.8 & 0.0 \\
\hline 비즈니스 스킬 (HR, 영업스킬 등) & $\square 1.12 .5$ & 2.0 & 2.3 & 3.0 & 4.5 & 0.0 & 1.7 \\
\hline 연기/춤 (뮤지컬, 비보이 등) & 0.81 .9 & 4.0 & 2.3 & 1.6 & 1.1 & 0.8 & 3.3 \\
\hline
\end{tabular}

[그림 1] 오픈서베이 취미생활·자기계발 트렌드 리포트 2020

[Fig. 1] Open Survey Hobby and Self-development Trend Report 2020 
특히 미술과 공예를 포함한 DIY (Do It Yourself) 시장, 즉 직접 만들어 쓰는 시장이 점차 커지고 범위도 넓어지고 있다. 맛집의 요리도 직접 만들어 먹을 수 있는 DIY 음식, 직접 완성하는 저렴하고 품질 좋은 조립형 DIY 가구, 정해진 위치에 물감만 칠하면 되는 DIY 명화도 있다. 이처럼 조금만 관심을 가지면 누구든 스스로 만들어 볼 수 있다. 과거에는 대다수의 창조활동이 먹고살기 위한 수단으로 활용되었다면 이제는 보다 윤택한 삶을 위한 수단으로 변모되 있다. 스스로 만들어내는 과정을 즐기고 창조 활동 자체에 가치를 두기 때문일 것이다.

트리즈는 이러한 창조 활동들과 마치 공생하는 생물과 같이 유기적 연계가 가능하다. 이것은 창조 활동에서 발생하는 다양한 문제가 트리즈를 접목해볼 기회를 낳고 직접 해결해나가는 과정을 통해 기법을 익힐 기회가 되기 때문이다. 만약 악기에 관심을 두고 있는 사람이 악기 제작을 하며서 트리즈도 함께 익힐 수 있다면 어려워 보이는 트리즈를 효과적으로 배우고 익힐 수 있는 기회가 될 수 있다.

따라서, 본 논문에서는 관심 분야 또는 취미활동 중에서 DIY 활동인 악기 제작과정의 문제를 트리즈에 접목해서 효율적으로 교육할 방법에 대한 연구를 진행하였다. 누구든 이해할 수 있도록 악기 중 가장 쉬운 구조로 되어 있는 제작하는 전반적인 과정에 나타난 문제들을 어떻게 트리즈적인 시각과 문제해결 마인드(mind)로 접근하여 풀어나가는지에 대해 연구하였다.

\section{2 심플플루트에 대한 개요}

그림 2 와 같이 심플플루트는 6개의 구멍을 지닌 취주 악기로 같은 개수의 운지 구멍을 가진 악기 중 아이리쉬 휘슬이 세로로 부는 것과 달리 가로로 부는 관악기이다.

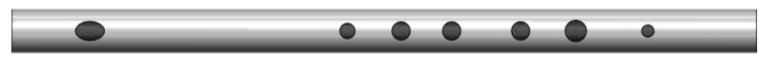

[그림 2] 심플플루트의 외형

[Fig. 2] The Appearance of a Simple Flute

특히 리코더와 같은 악기의 피플(Fipple: 악기의 마우스피스에 소리를 발생시키는 구조) 처럼 구조가 복잡하지 않고 단 한 개의 구멍으로 이루어진 마우스피스만으로 소리를 낼 수 있는 간단한 구조의 기명악기이다. 또한, 심플플루트는 만들기도 쉽고 운지법이 간단하기 때문에 많은 동호인이 직접 만들어서 연주하기도 한다.

이러한 형태의 악기를 대다수의 사람은 “가로 피리”라고 부르지만, 엄연히 “피리” 라는 명칭의 국악기가 존재하고 있기 때문에 비교적 간단한 구조를 지닌 이 악기를 일반적인 플루트와 구별하기 위해 Mark Shepard의 제작서인 "Simple Flutes" 의 내용을 참고하여 “심플플루트” 로 구분하기로 한다[3].

심플플루트의 왼쪽에 있는 가장 큰 구멍은 입으로 불어 소리를 내는 부분으로

“마우스피스" 라고 한다. 오른쪽에 있는 6 개의 구멍은 손가락으로 막고 여는 구멍으로 “운지구멍” 이라고 한다[그림 3]. 


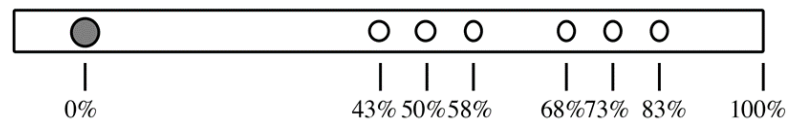

[그림 3] 심플플루트의 구멍위치 비율

[Fig. 3] Simple Flute Hole Position Ratio

심플플루트는 기본적으로 서양음악에 활용되고 있는 7음계의 악기로 조율하며 [그림 3]과 같이 각 구멍의 기본 위치가 악기의 전체 길이에 대한 비율로 정해진다. 일반적인 비율이므로 구멍의 크기를 크게 하거나 작게 하여 어느 정도 위치를 이동시킬 수도 있다. 이러한 방식으로 손가락의 간격을 일부 수정하여 연주 시 손가락의 움직임을 편안하게 조정할 수 있다. 악기의 음은 관의 직경과 길이에 의해 결정된다. 생성된 진동이 관의 고유진동 수와 공명을 통해 더 큰 소리를 발생시킨다[그림 4], [4].
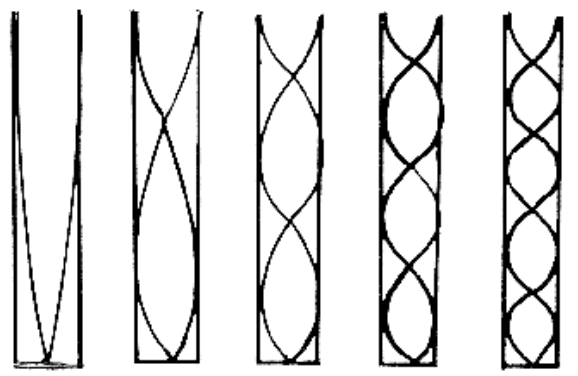

[그림 4] 관의 공명

[Fig. 4] Resonance of Tube

운지구멍을 열면 실제 길이 보다 짧은 길이의 관과 같은 효과를 낸다. 관악기는 이러한 효과를 이용하여 소리에 변화를 만들어 음계를 이루는 것이다. 심플플루트는 간단한 제작과정으로 만들 수 있지만 하나하나의 제작 단계마다 미묘한 문제들이 도사리고 있다. 소리가 나고 연주가 가능한 악기 제작을 위해 재료를 구하는 단계부터 최종 악기의 모습을 갖추는 데까지 발생된 문제들을 어떻게 해결해 나갈 수 있는지에 대한 방법을 각 제작 과정을 통해 정리하였다.

\section{3 제작과정}

심플플루트의 제작 과정은 [표 2]의 순서와 같이 정리할 수 있다. 악기의 이름으로 미루어보아 알 수 있듯이 악기의 구조, 연주 방식 그리고 제작 방법이 비교적 간단하다.

[표 2] 심플플루트 제작 순서

[Table 2] Sequence of Simple Flute Fabrication

\begin{tabular}{c|c|c}
\hline & 순서 & 설명 \\
\hline 01 & 재료준비 & 제작에 필요한 재료를 확보 \\
\hline
\end{tabular}




\begin{tabular}{l|c|c}
\hline 02 & 재료절단 & 필요한 길이로 자름 \\
\hline 03 & 가공표시 & 구멍 가공 위치 표시 \\
\hline 04 & 구멍가공 & 운지 및 소리구멍을 만들어 줌 \\
\hline 05 & 음정조율 & 조성에 맞춰 음정을 맞춤 \\
\hline 06 & 악기마감 & 악기의 외관을 다듬어 줌 \\
\hline 07 & 제작검수 & 최종 확인 및 연주 \\
\hline
\end{tabular}

심플플루트는 재료 준비와 구멍 가공이 전체 제작과정의 $80 \%$ 가 넘는 부분을 차지한다. 그래서, 우선 필요한 재료 즉, 자원을 어떠한 방법으로 찾고 이것을 원하는 형태로 가공하는 과정에서 발생한 문제를 어떻게 해결해나가는지 설명한다.

\subsubsection{FORS를 통한 자원 찾기}

모든 창조 활동들은 창조에 필요한 적합한 기능과 특성의 재료를 찾고 필요한 만큼 가공한 뒤 조합하여 원하는 결과를 만들어 간다. 조금이라도 더 원하는 것에 가까운 결과를 얻어내기 위해서는 적합한 도구를 활용할 수 있어야 한다. 적합한 도구가 없을 때는 주위 자원을 활용해야 한다. 재료 준비를 쉽고 빠르게 하기 위해 필요한 효율적인 개념 한 가지를 소개하고자 한다. 트리즈 이론에서 아이디어를 효율적으로 찾는 방방으로 FOS (Function-Oriented Search)라는 방법을 사용한다. FOS는 문제해결을 위해 필요한 기능을 이종 분야 즉, 다른 분야에 적용된 사례를 특허 분석 등을 통해 찾아서 내 문제해결에 적용하는 방법이다. 국제 트리즈 협회에서는 $\mathrm{FOS}$ 를 모던 트리즈의 핵심 방법으로 소개하고 있다. 의료 특허에 활용된 아이디어가 군사용이나 교육용으로 활용될 수 있다는 개념이다. 하지만 저자들은 본 논문에서 FOS를 수정한 FORS(Function oriented Resource Search) 방법을 제안한다. FORS는 문제해결에 적합한 기능을 수행할 수 있는 특성이 있는 자원을 찾는 방법을 의미한다[5].

세계 각국의 전통 관악기들은 주로 대나무로 만들어진 것이 많다는 것을 알 수 있다[그림 5].

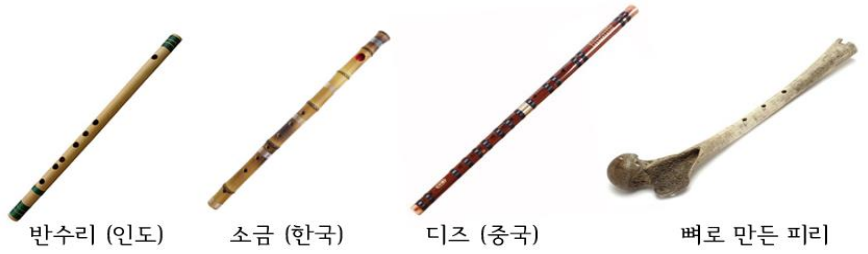

[그림 5] 악기의 소재

[Fig. 5] Musical Instrument Material

국악기의 단소, 피리, 대금, 소금 등도 대나무로 만들어진 악기에 속한다. 인도의 반수리와 중국의 디즈도 같은 소재인 대나무로 만들어진 악기이다. 이것은 과거에도 악기를 만들 때 이미 필요한 특성을 가진 자원을 찾아 활용해왔기 때문일 것이다. 심지어 사람의 뼈로 만든 악기도 출토되기도 했다. 뼈와 대나무는 완전히 다른 물성이지만 길이가 길고 외형이 둥글며 내부가 비어있는 특징은 같기 때문에 관악기를 
만드는데 필요한 자원이 되었을 것이다. 제작에 필요한 소재를 찾을 때는 먼저 자원이 필요한 요건 즉, Target을 설정하고 필요한 형상과 속성의 가용 자원이 얼마나 많은지 확인한다. 이때 가용자원의 너무 고가이면 사는 방향도 나쁘지 않은 선택이다.

악기 제작에 필요한 소재는 일반 가정에서도 찾을 수 있다. 악기의 재료라는 Target을 두고 FORS 과정을 거치면 필요한 요건을 갖춘 다양한 사물을 쉽게 찾아낼 수 있다[표 3].

[표 3] 악기제작을 위한 자원의 FORS 결과

[Table 3] FORS Result of Resources for Instrument Fabrication

커튼 봉, 걸레막대, 수도관, 안테나, 빨래건조대,

낚시대, 필기구, 등산스틱 등

이때 자원의 비용, 크기 또는 양 그리고 쉽게 이용할 수 있도록 접근성이 좋아야 한다. 가장 근접한 형태의 자원을 찾았지만 쉽게 이용할 수 없는 상태라면 자원의 특성을 참고하여 사면 된다. 이 논문에서는 비교적 쉽게 찾을 수 있는 수도관을 악기의 재료로 선정하였다. 그중에서도 구매 및 가공이 용이한 PVC 소재의 수도관을 대상으로 설명하기로 한다.

\subsection{2 물질-장을 활용한 소재 절단}

FORS 과정을 통해 마련된 커튼 봉이나 $\mathrm{PVC}$ 수도관과 같은 소재를 적절한 크기로 자르는 “절단” 과정을 거쳐야 한다. 일반 가정에서 톱과 같은 절단 도구가 없다고 가정해 보자. 이러한 상황에서 $\mathrm{PVC}$ 파이프와 같은 소재를 어떻게 자를 수 있을까? 여기서 우리는 물질-장을 활용하여 해결할 수 있다. 물질-장은 물질과 에너지장의 관계를 간단한 도형으로 표현하고 작용을 나타낸 일종의 다이어그램이다. 지구의 중력에 의해 떨어지는 사과 즉, 만유인력은 다음과 같이 표현할 수 있다[그림 6], [6].

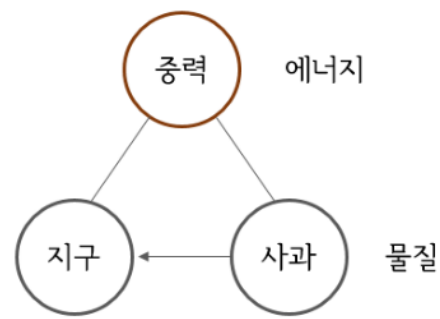

[그림 6] 만유인력 물질-장 모델

[Fig. 6] Material-field Model for Universal Gravitation

문을 두드릴 때 소리가 나는 것은 손의 두드리는 행위, 즉 기계적인 에너지가 문에 진동을 발생시키고 그 결과 소리인 음파로 나타난 것이다. 모든 작용은 사물과 대상 그리고 작용하는 에너지장으로 표현할 수 있다.

일반적으로 톱이나 칼과 같은 도구로 자를 수 있다. 하지만 빛이나 열로도 자를 수 있다는 것을 알고 있다. 강한 빛의 에너지 다발인 레이저로 자를 수 있고 강한 수압으로도 자를 수 있다. 우리가 잘라야 할 $\mathrm{PVC}$ 파이프는 염화비닐 소재이므로 
열가소성 특성을 가진 자원이다. 따라서, 열을 이용하여 자르는 것이 가능하다[그림 7].

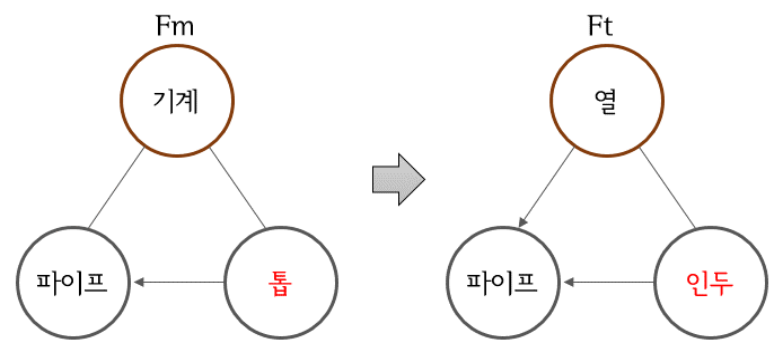

[그림 7] 소재 절단을 변화된 물질-장으로 표현

[Fig. 7] Expression of Material Cutting with Changed Material Field

이 과정에서 일반적으로 간과하기 쉬운 부분이 있다. 그것은 대상을 자른다는 개념이다. 목적을 잘 생각해보면 하나의 소재를 둘이나 그 이상으로 나누는 것이다. 절단의 사전적 개념은 물건을 도구로 자르거나 베는 행위를 말하는 것이다. 영어로 $\mathrm{Cut} /$ 컷 (off) 으로 표현할 수 있지만, 이것을 결과적 관점으로 보면 어떠한 물리적 에너지가 작용하여 결과적으로 대상이 “분리” 되는 상태를 만들어 낸 것이다. 따라서, 소재를 단순히 자른다기보다 조금 다른 시각으로 보면 둘로 나누어 분리한다고 생각할 수 있다. PVC 파이프를 자를 때 열을 직접적으로 이용하지 않아도 된다. 열을 간접적으로도 활용하여 자를 수 있다. 열을 파생자원 형태로 활용하여 자를 수 있다. [그림 8]과 같이 실을 파이프에 감고 마찰을 시켜 국소적 부분에 열을 발생시키고 이것을 반복하여 절단하는 것이다.

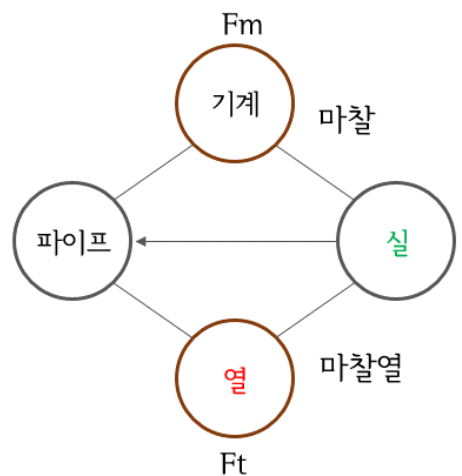

[그림 8] 파생자원의 활용

[Fig. 8] Utilization of Derivative Resources

이렇게 톱과 같은 절단 도구가 없더라도 가정에서 쉽게 찾을 수 있는 실이라는 자원과 마찰 작용을 통해 생성된 열이라는 에너지를 활용한 것이다.

과정인 “자르다” 에서 결과인 “나누다” 라고 생각을 변경하여 더 새롭고 다양한 방법을 발상할 수 있다. 아무리 복잡해 보이는 상황도 잘 관찰하면 모두 단순한 상황들이 중첩된 결과라는 것을 알 수 있다. 이처럼 복잡한 상황도 일반화를 통해 그 본질을 들여다보고 해결안을 찾을 수 있도록 하는 것이다.

소재에 미세한 구멍을 연속으로 계속 뚫어 나누는 방법, 케미컬을 활용하여 녹여 나누는 방법, 작은 틈을 만들고 넓혀서 나누는 방법들이 모두 소재가 분리되는 결과를 
얻을 수 있는 작용들이다.

\subsection{3 발명원리를 활용한 가공 위치표시}

필요한 크기로 재단된 소재를 연주할 수 있는 악기로 만들기 위해서는 정확한 위치에 구멍을 딿어주어야 한다. 따라서, 가공할 구멍의 위치를 소재의 표면에 표기하는 단계가 바로 가공 위치표시 단계이다. 6 개의 손가락 구멍과 1 개의 마우스피스 구멍의 위치를 표시한다. 그에 앞서 소재와 정확히 수평으로 일치하는 중심선도 그어주어야 한다.

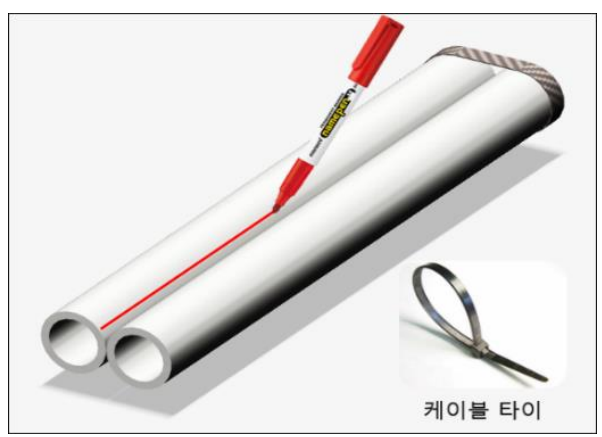

[그림 9] 파이프를 중첩시켜 선을 긋는 방법

[Fig. 9] To Draw a Line by Overlapping Pipes

$\mathrm{PVC}$ 와 같이 표면이 매끈하고 곡면인 소재에 중심선을 표기하는 것은 생각보다 쉽지 않다. 그나마 표기가 되더라도 명확하게 보이지는 않는다. 그리고, 가공 후에는 표기는 더 이상 필요하지 않으므로 깨끗이 지워야 한다. 40 가지 발명원리 중 04. 비대칭과 11. 사전예방조치를 활용하여 [그림 9]와 같이 둥근 표면에 수평선을 긋는 문제의 해결안을 얻을 수 있다. 즉, 동일한 파이프 하나를 더 붙여 줌으로써 표기 과정에서 둥근 파이프 형태의 소재가 굴러다니지 않게 하고 선을 긋는 기준 즉, 스스로 자와 같은 역할을 하게 된다.

그리고, 또 다른 해결안을 도출할 수 있다. 어차피 해야 할 것을 미리 해두는 것 즉, 발명원리 03. 국부적 품질과 발명원리 30. 유연한 엷은 막을 활용한 아이디어 발상으로 [그림 10]과 같이 해결할 수 있다[7].

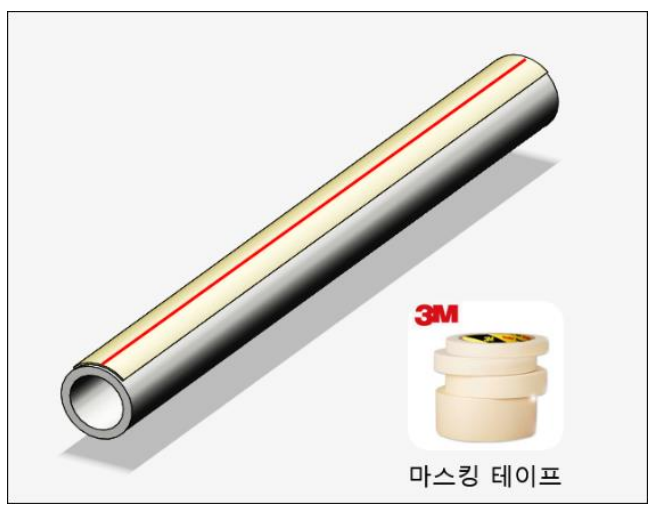

[그림 10] 마스킹 테이프를 활용한 가공 위치 표기

[Fig. 10] Use Masking Tape to Indicate where to Drill Holes 
표면에 아주 엷은 막인 마스킹 테이프를 부착시키고 부착한 마스킹 테이프 위에 표기하면 표기 문제를 쉽게 해결할 수 있다. 추가로 발명원리 10 . 사전조치 즉 미리 해두기를 적용하는 방법으로 미리 중심선을 그어둔 마스킹테이프에 부착하면 모든 문제를 한 번에 해결할 수 있다. 구멍 가공이 끝나면 파이프에 붙어있는 마스킹 테이프를 손쉽게 제거할 수 있다.

\subsection{4 구멍의 가공}

연주가 가능한 악기로 만들기 위해서 음정이 맞아야 하므로 정확한 위치에 구멍을 뚫어야 한다. 일반적으로 구멍을 뚫는 도구로는 전동공구인 드릴을 가장 많이 활용한다. 전동드릴에도 몇 가지 발명원리가 적용되어 있다. 드릴비트는 두 개의 조각도를 발명원리 07. 대칭성으로 맞붙여 놓은 형태이다. 이것을 발명원리 20. 유용작용인 회전 동작을 전동기의 작용으로 지속시킨 것으로 볼 수 있다. 전동드릴로 소재에 구멍을 뚫을 때 드릴비트에 의해 재료 내부가 손상되는 경우가 있다[그림 11].

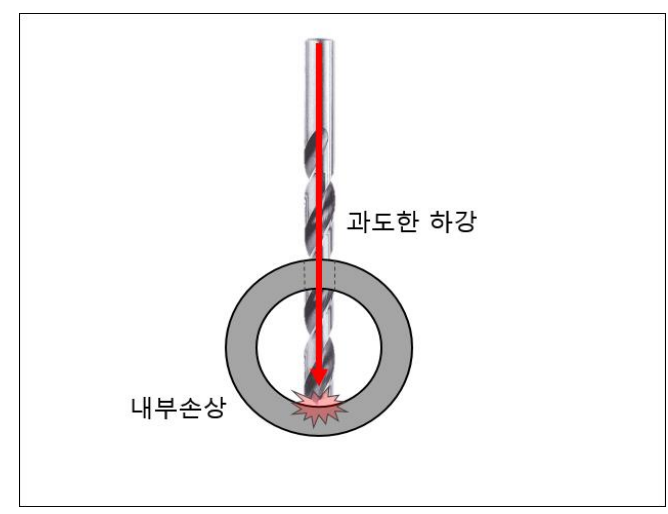

[그림 11] 드릴에 의한 내부 손상

[Fig. 11] Internal Damage by Drill

이 문제는 타공 작업 시 충분히 예측 가능한 문제이다. 따라서, 이러한 문제를 해결하기 위해서는 사전예방 즉, 안전조치를 해야 한다. 그림 10 과 같이 드릴비트에 더 깊게 내려가지 못하도록 스토퍼를 설치하여 길이를 한정시키면 파이프 내부에 불활성 환경이 조성된다. 따라서, 원하지 않는 현상을 예방할 수 있다. 드릴비트에 테이프를 몇 바퀴 감아 주어도 스토퍼를 적용한 것과 같은 효과를 얻을 수 있다. 유연한 엷은 막을 이용하여 불활성 환경을 만들어 내고 결국, 사전예방을 할 수 있게 되는 것이다. 이것은 스토퍼를 기준으로 드릴비트가 길기도 하고 짧기도 하도록 공간을 분리한 것이라 할 수 있다.

구멍을 뚫을 때 드릴과 같은 타공도구가 없어도 가공이 가능하다. $\mathrm{PVC}$ 는 열에 약한 열가소성 소재이다. 따라서, 높은 온도의 열을 낼 수 있는 자원이 있다면 해당 자원을 활용한 구멍 가공이 가능하다.

열을 이용하여 구멍을 똟는 방법도 다양하다. 전기인두로 녹여 뚫을 수 있고 못이나 송곳, 젓가락과 같은 금속 소재를 달궈서 구멍을 뚫을 수 있다. 


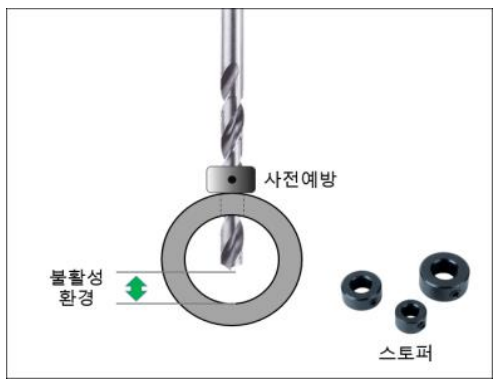

[그림 12] 내부 손상 방지

[Fig. 12] Prevent Internal Damage
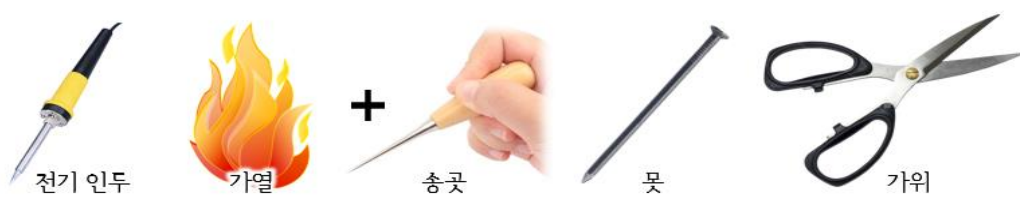

[그림 13] 열을 이용한 구멍가공 도구

[Fig. 13] A Tool that Uses Heat to Drill Holes

실제로 세계 각국의 전통악기 제작자들은 대나무와 같은 소재를 다양한 굵기의 금속 막대를 높은 온도로 달구어 악기의 운지구멍을 만들고 있다.

구멍을 한 번에 필요한 크기로 바로 뚫는 방법보다는 작은 구멍을 만들고 이 구멍을 가위의 빗면을 이용하여 적당한 크기로 넓히는 것이 더 나은 가공 결과를 얻을 수 있는 방법이다[그림13]. 이 처럼 결과를 만드는 방법이 정해진 하나가 아니고 매우 다양할 수 있다는 점이 중요한 포인트이다. 물질의 특성과 에너지장의 관계를 잘 활용하면 원하는 결과를 의외로 쉽게 얻을 수 있다.

\subsection{5 음정 조율}

구멍을 다듬어서 정확한 음정이 되도록 맞춘다. 하지만 실수로 구멍의 크기를 잘못 가공할 수도 있다. 이런 실수를 어떻게 예방하고 정확한 음정으로 조율 할 수 있을까? 발명원리 16. 과부족을 적용하여 실제 가공할 크기보다 조금 작게 뚫고 조율과정에서 넓히는 방법을 쓴다. 반대로 넓은 구멍을 좁게 하기는 매우 힘들기 때문이다.

조율 과정에서는 일반적으로 디지털 조율기를 활용하여 음정을 맞춘다. 최근 디지털 조율기는 과거보다 저렴한 비용으로 살 수 있지만, 조율기가 없더라도 스마트폰에 조율 프로그램을 설치하는 것만으로도 손쉽게 조율 작업을 수행할 수 있다. 기술은 이렇게 융합과 변화를 거듭한 끝에 실체가 없어도 기능이 남는 형태로 진화한다. 트리즈는 이러한 “기술진화의 법칙” 에 대해서도 이미 연구되어 있다. 음정을 맞출 때는 줄(file)이나 사포(Sand Paper)를 이용하여 운지 구멍을 갈아낸다. 이때 전동 그라인더를 쓰면 좀 더 빠르게 작업할 수 있지만 정교한 작업을 위해서는 수작업을 선호한다.

\subsection{6 악기 마감}

제대로 된 악기로 완성하기 위해서 악기의 표면을 다듬고 장식 등의 과정을 통해 조금 
더 가치를 높일 수 있다. 좋은 악기로 완성하기 위해서 표면 마감은 중요한 과정이다. 나무로 된 국악기가 습기에 약하므로 내부를 도장한다. 그리고, 갈라지지 않도록 명주실로 단단히 감아준다. 오카리나와 같은 도자기 악기는 소성 과정에서 연기를 인위적으로 먹여서 외관을 검게 하여 오염에 강하고 고급스럽게 한다. 이러한 것들이 모두 악기 마감에 해당한다.

반면 PVC 수도관으로 제작한 악기는 갈라지지도 않고 습기에도 강하다. 다만 외관이 고급스럽지 못하고 단순하다는 것이 문제이다. 따라서, $\mathrm{PVC}$ 소재이지만 외관을 돋보이게 만드는 과정을 거친다. 목재는 고급 악기에 많이 적용하는 소재이다.

악기를 나무로 만들고 싶지만 나무를 원통으로 가공할 수 있는 설비가 없다면 쉽지 않은 일이다. 하지만, 무늬목을 사용하여 해결할 수 있다. 무늬목은 나무를 종이처럼 얇게 깎은 나무로 포장이나 장롱 등의 장식하기 위해 쓰이는 소재이다. 얇은 무늬목을 목공풀로 겹겹이 붙여서 목표한 형상으로 만든 것이다. 발명원리로 표현하면 유연한 엷은 막을 중첩, 포개기로 구현한 것이다. 만약 눈에 보이는 외관만을 나무로 보이는 것을 목표로 한다면 제일 바깥쪽에만 붙여주면 된다. 유연한 엷은 막을 국소적으로 적용하여 해결한 것이다. 엷은 소재를 중첩한 것이지만 실제로 나무와 특성이 같기 때문에 표면을 바니쉬 등의 마감재를 발라주어 표면 강도를 향상시킬 수 있다.

\subsection{7 악기의 완성}

모든 단계의 제작 과정이 끝나면 악기의 조성과 자신만의 로고를 악기 표면에 표시하고 최종 연주를 통해 음정, 음량, 음색 등을 확인한다. 제작의 각 단계에서 발생한 문제들을 트리즈 도구를 활용하여 해결했기 때문에 완성된 악기에는 특별한 문제가 발생하지 않는다. 이로써 연주가 가능한 DIY 심플플루트가 완성되었다.

\section{4 제작 문제 해결 결과}

제작 과정상의 문제를 모두 해결하면 다음과 같은 다양한 형태의 악기들을 만들어 낼 수 있다.

[표 4] 완성된 악기의 종류

[Table 4] Types of Instruments Completed in Production

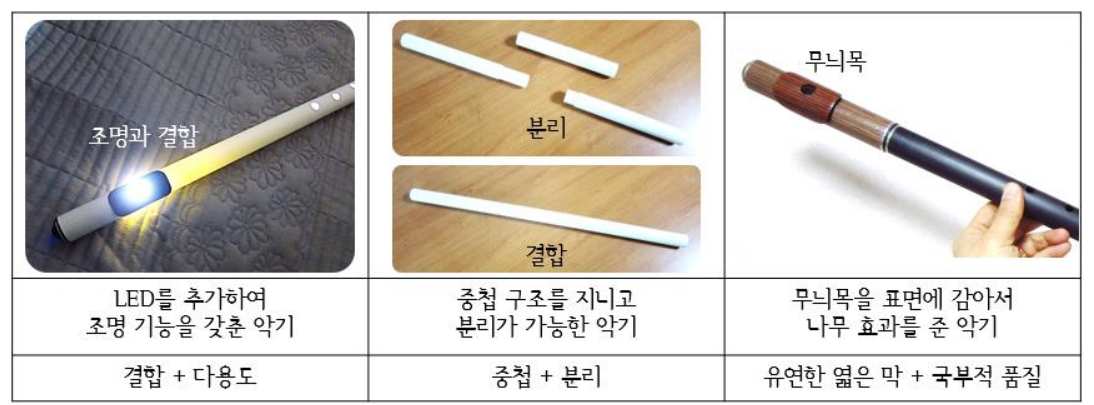

[표 4]와 같이 내부에 조명을 추가하거나 여러 조각으로 결합이 가능한 분리형 악기 등 목적에 따라 다양하고 독특한 악기를 만들 수 있었다. 세 번째 사진의 악기는 표면에 
엷은 무늬목을 여러 겹 감아 나무의 느낌 살린 것이다. 이외에도 분리 및 통합을 통해 다양한 Key로 가변되는 악기, 구멍을 비스듬히 타공하여 편안한 운지 간격을 가지도록 한 악기, 엷은 소재의 관을 여러겹으로 중첩시켜 작게 접을 수 있도록 한 악기, 중첩된 부분의 길이를 변화시킬 수 있어 음정 조절이 가능한 악기 등 제작자의 컨셉과 의도를 반영한 다양한 악기를 제작할 수 있다.

\section{3. 악기 DIY와 트리즈의 연계학습 결과}

\section{1 학습의 트리즈적 결과}

간단한 심플플루트를 제작하는 과정이지만 트리즈 도구를 전반적으로 접목해 해결해나가는 것이 가능하였다. 물론, 트리즈를 전혀 배우지 않은 미학습자의 입장에서는 $\mathrm{DIY}$ 와 트리즈를 접목한다는 것은 어려울 수 있다. 트리즈 1수준 정도의 입문 과정을 이수한 학습자가 실무에 적용하기에 앞서 본인의 관심사를 바탕으로 접목해보는 것은 좋은 연습 과정이 될 수 있다. 제작과정에서 계속해서 나타나는 문제 상황을 연습문제 형태로 풀어볼 수 있었고 이것을 해결하기 위한 아이디어 발상을 계속해 나갈 수 있어서 해결 도구를 학습하는 데 도움이 되었다. 새로운 문제가 연이어 나타나더라도 오히려 스스로 문제를 발굴하고 정의하는 과정이 반복되어 강화된 학습효과를 얻을 수 있었다. [표 5]

[표 5] 트리즈 관점의 학습 결과

[Table 5] Learning Outcomes from a TRIZ Perspective

복잡한 상황에서 문제를 찾을 수 있다.

모순/상충 상황을 찾을 수 있다.

타겟 즉, IFR을 정의할 수 있다.

발명원리로 해결안을 발상할 수 있다.

분리원리로 아이디어를 발상할 수 있다.

문제상황과 트리즈를 연계할 수 있다.

\section{2 악기 제작 결과}

악기를 제작할 때에는 좀 더 빨리, 좀 더 정확히, 좀 더 쉽게, 좀 더 조용히, 좀 더 완벽한 악기 완성의 욕구가 생긴다. 트리즈는 이러한 욕구를 충족시키도록 도와준다. $\mathrm{FORS}$ 를 통해 이미 $70 \%$ 이상 근접한 소재로 제작하므로 제작 시간은 기존보다 현격히 단축할 수 있었다. 그리고, 저자의 경우 일정한 구멍 가공을 돕는 도구, 길이를 쉽게 측정하고 재단할 수 있는 도구, 정확한 절단 각도를 유지시키는 도구 등 발명원리를 기반으로 다양한 $\mathrm{Jig}$ 들을 제작하여 활용하고 있다. 그렇기 때문에 제작의 편의성과 정확성을 향상할 수 있었다[표 6].

악기 제작에서는 적은 비용으로 더 빠르게 완성도 높은 악기의 제작할 수 있게 되었다. 악기에서 완성도가 높다는 것은 우선 음량이 크고 음정이 잘 맞는 악기를 말하는 것이지만 연주하기 편한 악기라야 한다. 트리즈의 다양한 기법들을 활용하면 좀 더 이상적인 형태의 악기를 안정적으로 제작할 수 있다. 제작 과정이 안정적이면 제작된 
악기도 안정적인 소리를 내어주며 직접 제작하기 때문에 제작자의 손에 맞는 편안한 연주가 가능한 악기로 만들 수 있다.

[표 6] 악기제작 관점의 학습 결과

[Table 6] Learning Outcomes from a Musical Instrument Manufacturing Perspective

필요한 재료를 쉽게 찾을 수 있다.

악기의 완성도를 높일 수 있다.

보다 빠르고 편리하게 만들 수 있다.

독창적이고 새로운 악기를 만들 수 있다.

[그림 14]는 악기의 가치를 끌어올 수 있도록 플루트의 끝부분에 FORS를 통해 찾은 의류용 단추를 헤드 크라운으로 적용하여 완성한 것이다.

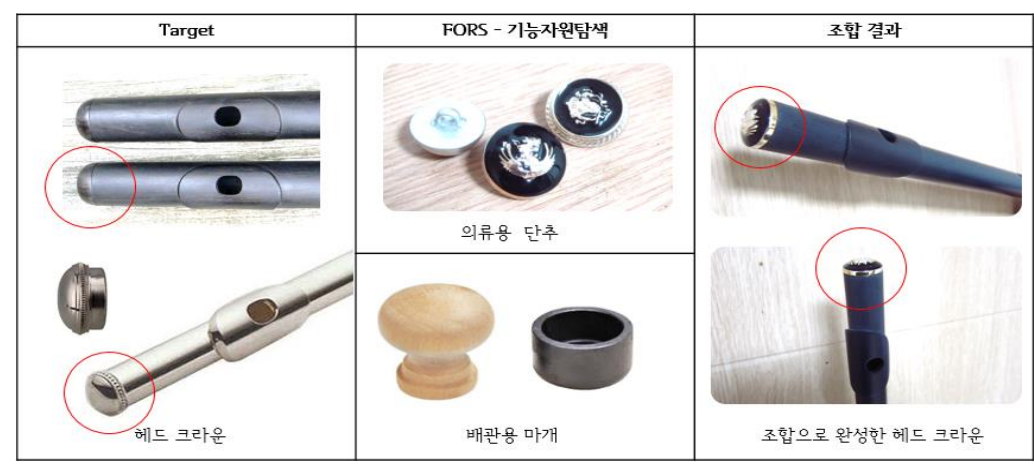

[그림 14] FORS로 찾아낸 자원을 헤드 크라운으로 적용

[Fig. 14] FORS-Found Resources to Head Crown

[그림 15]는 플루트를 세워서 보관할 수 있는 악기 스탠드에 대해 FORS를 실시하여 냄비 받침대와 도어스토퍼를 조합하여 완성할 수 있었으며 최소 비용으로 목표한 결과를 얻을 수 있었다. 완성된 악기 스탠드의 하부에는 미끄러짐을 방지하고 견고한 악기 지탱이 가능하도록 고무 받침을 세 군데 추가해주어 안정성을 높여주었다.

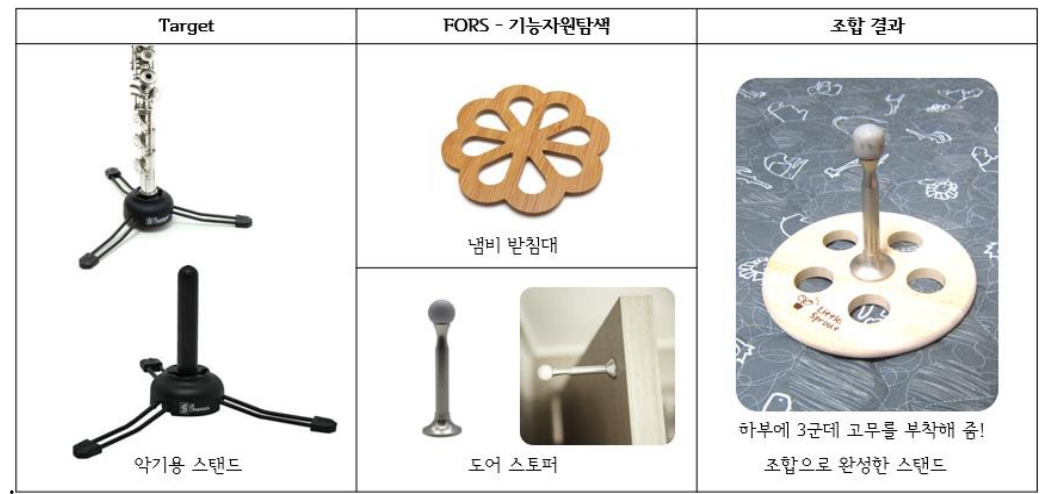

[그림 15] FORS로 찾은 자원을 조합하여 악기용 스탠드 형성

[Fig. 15] Combining Resources Found by FORS to Form a Stand for Instruments 
연주가 가능한 악기를 쉽고 빠르게 만들 수 있으며 제작과정 전반에 다양한 트리즈 도구의 접목이 가능하므로 실제 상황의 문제를 통해 트리즈 기법들을 체득할 수 있다는 것을 알 수 있다. 필드의 다양한 문제들도 유사한 방식으로 해결할 수 있기 때문에 현장 문제해결 능력을 확보할 수 있다.

\section{4. 결론}

모든 교육과정의 학습효과는 학습자의 몰입도에 큰 영향을 받는다. 특히 트리즈와 같은 창의적 문제해결 도구는 문제를 해결하고자 하는 의지가 부족하면 좋은 결과를 얻어낼 수 없을 뿐만 아니라 쉽사리 포기하고 만다. 따라서, 특정 분야의 전문성과 지식을 어느 정도 겸비하여야 하고 해당 분야에서 발생한 문제를 스스로 포착해 내었을 때 자연스럽게 몰입하게 되고 동시에 문제해결 의지를 끌어올릴 수 있다.

본 연구에서 학습자의 관심 분야를 바탕으로 트리즈를 학습하는 것은 흥미와 몰입을 자연스럽게 끌어내 학습효과를 높이는 방법임을 확인 할 수 있었다. 특히 공예나 DIY와 같은 제작 과정과의 연계는 창작활동에서의 발생한 문제가 트리즈 학습 시 풀어볼 재료로 즉시 활용될 수 있다. 따라서, 트리즈 도구를 적용해 이론을 배움으로써 학습의 효과를 높일 수 있다.

\section{5. 감사의 글}

This research was supported by Basic Science Research Program through the National Research Foundation of Korea (NRF) funded by the Ministry of Education (2018R1D1A1B07049244).

\section{References}

[1] H. J. Kim, Theory of Inventive Problem Solving TRIZ, Wisdom Publishing, (2004), pp.42-44.

[2] http://www.opensurvey.co.kr/Hobby and Self-development Trend Report 2020, Jan 20 (2021)

[3] Mark Shepard, Simple Flutes: A Guide to Flute Making and Playing, or How to Make and Play Simple Homemade Musical Instruments from Bamboo, Wood, Clay, Metal, PVC Plastic, or Anything Else, Simple Productions, (2018)

[4] https://divine-arts.org/soundgarden/makingmusic/winds_brass.htm, Dec 26 (2020)

[5] S. S. Litvin, New TRIZ based tool - function-oriented Search, Paper presented at the 7th Annual Conference of the Altshuller Institute for TRIZ Studies, (2005), April 17-19; Detroit, USA.

[6] Y. W. Song, K. M. Kim, S. H. Kim, Material Field Analysis and Standard Solution, Creative Problem Solving Theory TRIZ, KSA Media, (2017)

[7] I. C. Kim, Secrets of Wisdom, Contradictions and Solutions, MJ Media, (2012) 